\title{
Landslide Susceptibility Estimation Using GIS. Evritania Prefecture: A Case Study in Greece
}

\author{
Georgios Ntelis, Stavropoulou Maria, Lekkas Efthymios \\ National and Kapodistrian University of Athens-Sector of Dynamic, Tectonic \& Applied Geology, Athens, Greece \\ Email: geontelis@geol.uoa.gr
}

How to cite this paper: Ntelis, G., Maria, S., \& Efthymios, L. (2019). Landslide Susceptibility Estimation Using GIS. Evritania Prefecture: A Case Study in Greece. Journal of Geoscience and Environment Protection, 7, 206-220.

https://doi.org/10.4236/gep.2019.78015

Received: July 9, 2019

Accepted: August 23, 2019

Published: August 26, 2019

Copyright $\odot 2019$ by author(s) and Scientific Research Publishing Inc. This work is licensed under the Creative Commons Attribution International License (CC BY 4.0).

http://creativecommons.org/licenses/by/4.0/

\begin{abstract}
Nowadays, natural hazards constitute an integral part in the everyday reality of people's lives. A landslide event, although usually occurring at a low frequency (compared to other hazards), may develop into a major natural disaster involving extensive and adverse effects, both in the natural and man-made environment. Thus, by making this assumption and combining it with the human mentality that has the tendency to reassure and resist extreme physical processes, the underlying danger "in total", is multiple of what is expected. Therefore, studying of this phenomenon is so important in many areas. Because of the climate conditions, geologic and geomorphologic characteristics of the region, the purpose of this study was the landslide hazard assessment by using Fuzzy Logic, Frequency Ratio and Analytical Hierarchy Process method in the Evritania prefecture. At first, landslides occurring in Evritania prefecture, were identified using a landslide database from Institute of Geology \& Mineral Exploration of Greece and by primary field studies. The influence landslide factors used in this study were slope, aspect, elevation, lithology, precipitation, land cover, distance from faults and distance from rivers, were obtained from different sources and maps. Using these factors and the identified landslides, the fuzzy membership values were calculated by frequency ratio. Then, to account for the importance of each of the parameters in the landslide susceptibility, weights of each factor were determined based on the Analytical Hierarchy Process method. Finally, fuzzy map of each factor was multiplied to its weight that obtained using AHP method and at the end-for computing prediction accuracy-the produced map was verified by comparing to existing landslide locations. These results indicate that the three methods Fuzzy Logic, Frequency Ratio and Analytical Hierarchy Process method are relatively good estimators of landslide susceptibility in the study area. According to landslide susceptibility area map, about $50 \%$ of the occurred landslide fall into high and very high susceptibility zones and also approximately $21 \%$ of them indeed located in the low and very low susceptibili-
\end{abstract}


ty zones.

\section{Keywords}

Natural Hazards, Landslide Susceptibility, Frequency Ratio

\section{Introduction}

Landslides, as one of the most important natural hazards, occur in many different areas throughout the world, chiefly in mountainous and hilly areas. Globally, landslides cause the loss of life and property, damage natural resources and infrastructures such as road networks and bridges (Conforti et al., 2012). In addition, direct and indirect costs of landslide occurrence exceed millions of dollars all over the world. Landslide susceptibility is defined as the proneness of the terrain to produce slope failures and it is usually expressed in a cartographic way. A landslide susceptibility map depicts areas which likely have landslides in the future by correlating some of the principal factors that contribute to landslides with the past distribution of slope failures (Brabb, 1984).

Up to now, several algorithms and models have been proposed for generating landslide susceptibility, mainly including Analytical Hierarchy Process-(AHP) (Khezri, 2010), Logistic Regression (Carrara, 1983), Fuzzy Logic (Gee, 1991), Artificial Neural Network (ANN) analysis (Caniani et al., 2008), modeling approaches (Perriello Zampelli et al., 2012), Fuzzy Analytical Hierarchy Process (Liu et al., 2007), Geographically weighted principal component analysis (Faraji Sabokbar et al., 2014) etc., most of which are related to the weight of landslide factors. So, undoubtedly, the above studies demonstrate that many techniques have been used for landslide susceptibility mapping and have achieved excellent results.

Therefore, FAHP method, as a common and important technique for landslide susceptibility mapping, was used to create a landslide susceptibility mapping for Evritania prefecture in Greece. Note that the main difference between the present study and the approaches described before is the combination of three models (AHP, Fuzzy Logic and Frequency Ratio) to calculate landslide susceptibility hazard in Evritania prefecture. Therefore, it is predicted to have more accurate results rather than in past studies. In conclusion, it can be written that landslides are a major geohazard and can be triggered either by earthquakes, volcanic eruptions, flood, or by man-made activities.

\section{Study Area}

Evritania prefecture is located in central Greece region between longitudes $21^{\circ} 20^{\prime} \mathrm{E} \& 22^{\circ} 00^{\prime} \mathrm{E}$, and latitudes $38^{\circ} 40^{\prime} \mathrm{N} \& 39^{\circ} 15^{\prime} \mathrm{N}$ with its extent amounts to $1868.9 \mathrm{~km}^{2}$. The average altitude is 1042 meters; the average slope is $21^{\circ}$ and forest areas cover $45 \%$ of the study area. According to Hellenic Statistical Agency 
(2011) the population stands at 20,081 inhabitants while having the highest index of mountainousness that reaches 2.89 which is based on multi-criteria such as the average altitude, average slope and percentage of mountain communities. Furthermore, the oreographic axes have a NE-SW direction, while in the southern of prefecture are transverse axes to the previous. It is mentioned that the main feature of the prefecture is the intense and inaccessible relief with frequent chasms. Mean annual precipitation and temperature within the study area for the last sixty years (1957-2017) are $1353 \mathrm{~mm}$ and $10.1^{\circ} \mathrm{C}$ respectively. The tectonic of the area is representative of the Pindos mountain range tectonic, characterized by large folds and successive thrusts from east to west. The folds followed burglaries with vertical faults. Regarding geology of the study area, the main geological units are limestone (42\%) and flysch (40\%). Location map of Evritania prefecture is shown in Figure 1.

\section{Data}

The identification of influence factors for landslide events constitutes the basis of many methods to determine susceptibility assessment. These factors, which are triggering or activating the phenomenon, can be separated into three (3) broad categories as it is shown in text below: 1) topographic, 2) geological and 3) environmental (Crozier \& Glade, 2005). In present study totally nine (9) influence factors have been considered. Briefly, these are lithology, elevation, land use, slope, aspect, precipitation, hydroperability, distance from faults and from river (see Figure 2) and the reasons that they have been selected are explained for each one below:

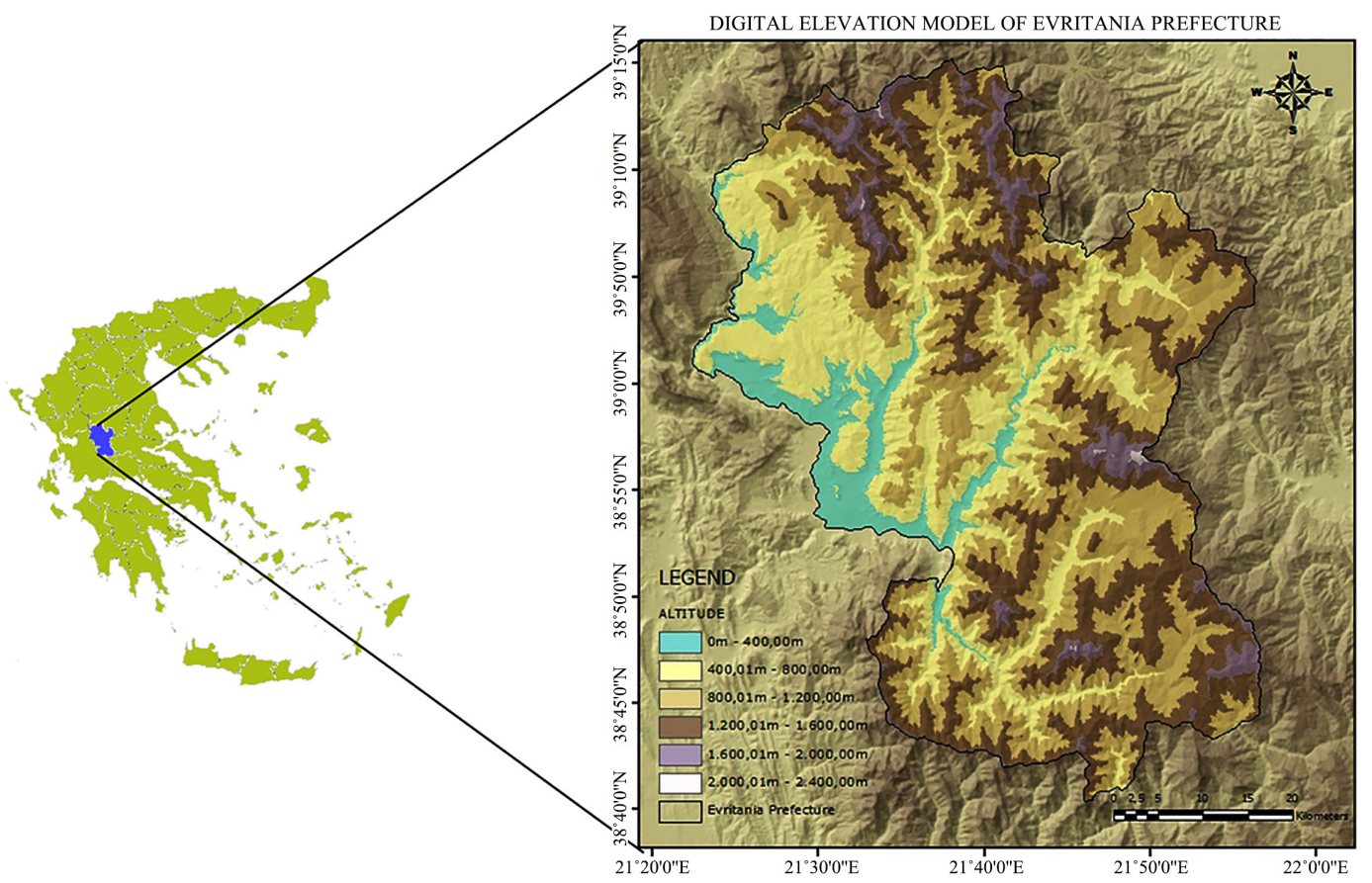

Figure 1. Location map of study area. 

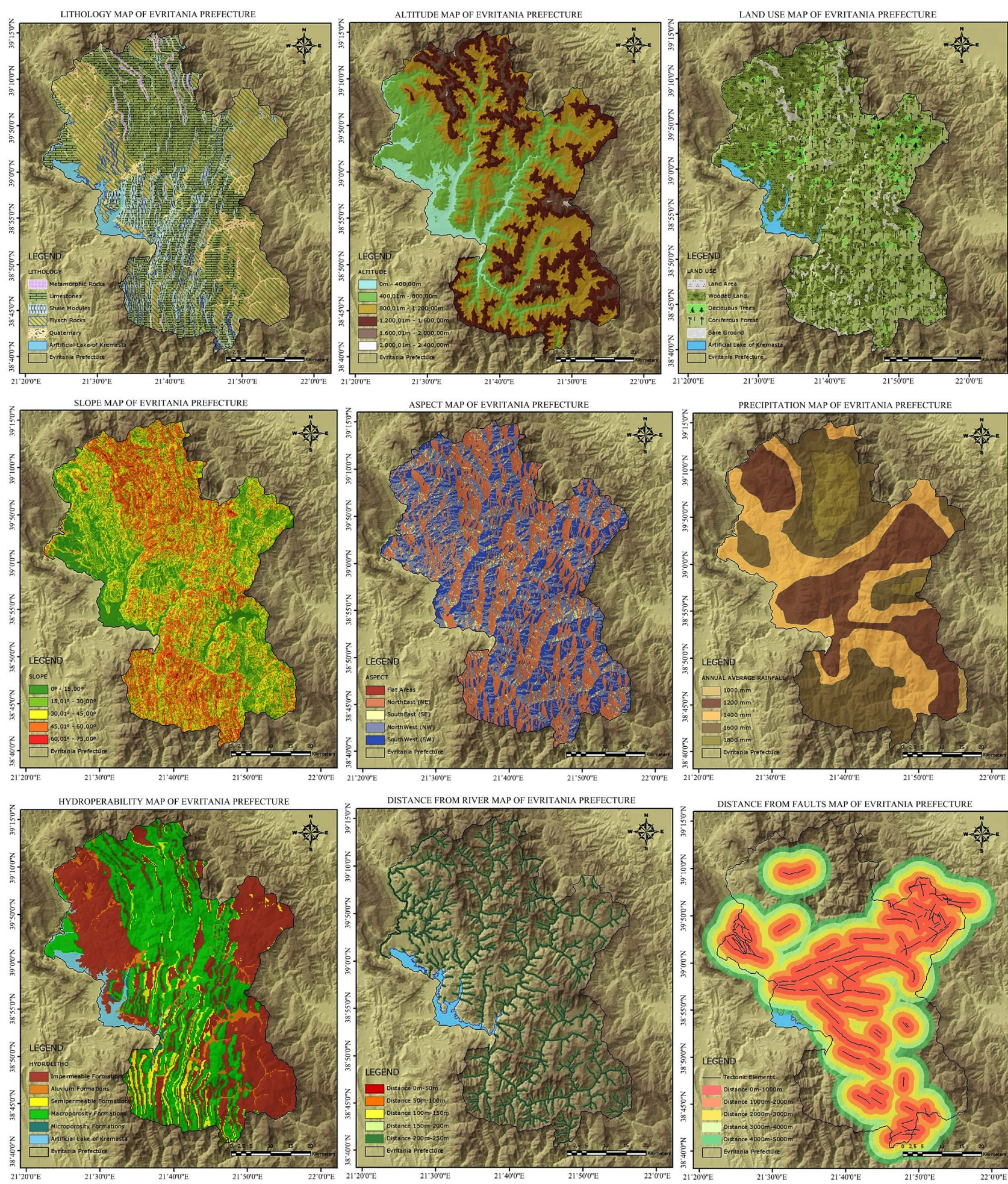

Figure 2. Landslide susceptibility factors.

- Lithology: It has been widely recognized that lithology greatly influences the occurrence of landslides because lithological and structural variations often lead to a difference between the strength and permeability of rocks and soils (Champati Ray et al., 2007). Moreover, lithology is one of the main factors 
for landslide susceptibility zonation (Kayastha et al., 2013).

- Elevation: Most researchers use elevation as a controlling parameter for landslides (Creighton, 2006) and some other have found that landslide activity (within a specific basin) occurs at certain elevations. As a result, the relationship between landslide activities and elevation is still unclear; hence it requires further studies (Hatamifar et al., 2012).

- Land use: Landslides are natural responding phenomena and will occur whether people are there or not. However, human practice may accelerate the occurrence or play a significant role in the occurrence of landslides (Cheng \& Wang, 2007). Land use is mainly dominated by various types of woods, rangeland, grassland residential area and cultivated land (Dai et al., 2001).

- Slope: Is considered as one of the major factors in landslide susceptibility map because slope has direct effect on landslide process; therefore, it is frequently used in landslide susceptibility map (Ayalew \& Yamagishi, 2005; Jordan et al., 2000).

- Aspect: Aspect-related parameters such as exposure to sunlight, drying winds, rainfall (wetness or degree of saturation) and discontinuities may possibly control the occurrence of landslides. In the present study, aspect is divided every $90^{\circ}$ and one class refers to flat areas. Thus, there are 5 intervals.

- Precipitation: Most of the landslide phenomena occur after heavy rainfall; so that water infiltrates rapidly upon heavy rainfall and increases the degree of saturation and potential of landslide occurrence (Pourghasemi et al., 2009). Average annual rainfall for a sixty-year period (1957-2017) in this case study is $1353 \mathrm{~mm}$; thus, precipitation is one of the major parameters in the area.

- Hydroperability: Porosity is a measure of how much water can be stored into the geological materials. Almost all rocks are containing some porosity and therefore contain groundwater. In addition, porosity gives a description of how much space there could be to hold water under the ground and permeability describes how those pores are shaped and interconnected. Consequently, hydroperability and groundwater have a significant role in causing landslides.

- Distance from streams: Generally, potential of landslides increases by decrease in distance to rivers, because streams may adversely affect stability by eroding the slopes either by saturating the lower part of material, resulting in water level increases (Ercanoglu \& Gokceoglu, 2004).

- Distance from tectonic elements: Tectonic elements and most faults are the structural features which describe a zone of weakness with relative movement, along which landslide susceptibility is higher (Pourghasemi et al., 2009). It has generally been observed that the probability of landslide occurrence increases as the mentioned distance decreases, which not only affect the surface material structures but also make contribution to terrain permeability causing slope instability (Iovine, 2008).

Furthermore, in order to accomplish the landslide susceptibility analyses in the study area, a spatial database was designed and developed. Spatial analysis 
tools were implemented within Geographic Information System environment with the use of Arc Map (version 9.3) software package. This database comprises two main parts. In the first part are included datasets with background of geographic conditions such as slope, lithology, land cover, etc. and the second part compacts the whole landslide inventory dataset. It is highly noted that a spatial dataset which represents former landslides is the most critical information layer in order to implement quantitative statistical analysis for landslide susceptibility assessment. In the present paper, two main landslide inventories were used: 1) an inventory maintained by Institute of Geology and Mineral Exploration (IGME) formed only from the recent historical records, covering a time period 1957-2017; and 2) observed records developed on the basis of fieldwork interpretation. The landslide map is in the form of point coverage, the topographic map in the form of line and point coverage at a scale of 1:50,000; the geological map in the form of polygon coverage at a scale of 1:50,000.

Totally nine (9) landslide factors extracted from the constructed spatial database, were considered when calculating the probability. Contour and survey base points that have elevation value were extracted from the topographic map and were made by using the elevation value. The slope, aspect, and elevation were obtained from the Digital Elevation Model (DEM) using IDW model. The distance from river and tectonic elements was calculated using the topographic map. A lithology and tectonic map of the study area is digitized from the existing geology map at the scale of 1:50,000 from the Institute of Geology and Mineral Exploration in Greece (IGME). Finally, land cover data was digitized and classified from CORINE land cover database 2018.

\section{Methodology}

Analytic hierarchy process (AHP) is a multi-criteria decision-making method that was originally developed by Professor Thomas Saaty. AHP is one of the most suitable approaches for decision making and most commonly used method for assessment which works base on a premise that decision making of complex problems can be handled by structuring the complex problem into a simple and comprehensible hierarchical structure. Despite its wide range of applications, the conventional AHP approach may not reflect a style of human thinking, in which human's judgments are represented as exact numbers. However, in many practical situations, decision makers usually feel more confident to give interval judgments rather than expressing their judgments in the form of exact numeric values. Therefore, this technique involves subjectivity in pair-wise comparisons and vagueness and uncertainty dominate in this process. Combining AHP into the fuzzy system brings the fuzzy number of the fuzzy set theory directly into the pair-wise comparison matrix of the AHP. The purpose is to solve vague problems, which occur during the analysis of criteria and the judgment process. FAHP should be able to tolerate vagueness or ambiguity, and should thus be more appropriate and effective than conventional AHP in real practice. A fuzzy set is a class of objects with continuous grades of membership which represents 
the degree of truth as an extension of valuation. Fuzzy sets generalize classical sets while the indicator functions of these sets are special cases of the membership functions of fuzzy sets for the latter only take values 0 or 1 . Therefore, fuzzy analytic hierarchy process (FAHP), a fuzzy extension of AHP, was developed to solve the hierarchical fuzzy problems. In the FAHP procedure, the pair-wise comparisons in the judgment matrix are fuzzy numbers that are modified by the designer's emphasis. In order to create the landslide susceptibility map, the frequency ratio model was first used for calculating fuzzy membership. As previously mentioned, the frequency ratio is the ratio of the area where landslides occurred in the total study area, and also is the ratio of the probabilities of a landslide occurrence to a non-occurrence for a given attribute (Bonham-Carter, 1994). Below in text it is shown Equation (1) which calculates the frequency ratio index and Table 1 where presented the main characteristics of landslide factors.

$$
F R=\frac{D_{i} / A_{i}}{\sum_{i=1}^{N} D_{i} / \sum_{i=1}^{N} A_{i}}
$$

$D_{i}:$ is the area of landslide of the $i$ category,

$A_{i}:$ is the area of the $i$ category in a certain parameter,

$N$ : is the category number of the parameter.

Table 1. Spatial relationships between each landslide factor and fuzzy membership values.

\begin{tabular}{|c|c|c|c|c|c|}
\hline $\begin{array}{l}\text { Landslide } \\
\text { Factor }\end{array}$ & $\begin{array}{c}\text { Classification } \\
\text { Category }\end{array}$ & $\begin{array}{c}\text { Landslide } \\
\text { Frequency (\%) }\end{array}$ & $\begin{array}{l}\text { Hierarchy } \\
\text { Ranking }\end{array}$ & $\begin{array}{c}\text { Area of } \\
\text { class }\left(\mathrm{km}^{2}\right)\end{array}$ & $\begin{array}{l}\text { Frequency } \\
\text { Ratio Index }\end{array}$ \\
\hline \multirow{6}{*}{ Lithology } & Shale modules & 2.86 & 1 & 216.23 & 0.17 \\
\hline & Limestones & 3.57 & 2 & 735.92 & 0.09 \\
\hline & Metamorphic & 7.86 & 3 & 26.44 & 0.65 \\
\hline & Flysch rocks & 41.07 & 6 & 745.82 & 1.55 \\
\hline & Quaternary & 26.07 & 5 & 20.51 & 2.10 \\
\hline & Recent deposits & 18.57 & 4 & 72.92 & 1.98 \\
\hline \multirow{5}{*}{$\begin{array}{c}\text { Water } \\
\text { permeability }\end{array}$} & Impermeable & 41.07 & 4 & 826.55 & 2.45 \\
\hline & Semipermeable & 5.71 & 3 & 128.33 & 0.45 \\
\hline & Macro-porosity & 3.57 & 1 & 779.94 & 0.10 \\
\hline & Micro-porosity & 5.00 & 2 & 10.10 & 0.73 \\
\hline & Alluvium & 44.64 & 5 & 72.92 & 3.75 \\
\hline \multirow{5}{*}{$\begin{array}{c}\text { Distance from } \\
\text { streams }\end{array}$} & $0 \mathrm{~m}-50 \mathrm{~m}$ & 38.21 & 5 & 111.08 & 2.30 \\
\hline & $50 m-100 m$ & 28.57 & 4 & 118.79 & 1.66 \\
\hline & $100 \mathrm{~m}-150 \mathrm{~m}$ & 15.72 & 3 & 127.13 & 0.82 \\
\hline & $150 \mathrm{~m}-200 \mathrm{~m}$ & 12.14 & 2 & 135.22 & 0.60 \\
\hline & $200 m-250 m$ & 5.36 & 1 & 143.41 & 0.12 \\
\hline
\end{tabular}




\section{Continued}

\begin{tabular}{|c|c|c|c|c|c|}
\hline \multirow{6}{*}{ Elevation } & $0 m-400 m$ & 1.43 & 1 & 135.46 & 0.19 \\
\hline & $400 \mathrm{~m}-800 \mathrm{~m}$ & 3.93 & 2 & 470.51 & 0.05 \\
\hline & $800 m-1200 m$ & 31.79 & 5 & 686.31 & 1.55 \\
\hline & $1200 \mathrm{~m}-1600 \mathrm{~m}$ & 41.07 & 6 & 479.17 & 2.22 \\
\hline & $1600 m-2000 m$ & 17.14 & 4 & 95.47 & 1.39 \\
\hline & $2000 m-2400 m$ & 4.64 & 3 & 2.75 & 1.00 \\
\hline \multirow{5}{*}{$\begin{array}{l}\text { Distance from } \\
\text { faults }\end{array}$} & $0 \mathrm{~m}-1000 \mathrm{~m}$ & 31.43 & 5 & 837.08 & 1.94 \\
\hline & $1000 \mathrm{~m}-2000 \mathrm{~m}$ & 26.07 & 4 & 1395.16 & 1.21 \\
\hline & $2000 m-3000 m$ & 18.57 & 3 & 1953.46 & 1.03 \\
\hline & $3000 m-4000 m$ & 14.29 & 2 & 2512.07 & 0.35 \\
\hline & $4000 m-5000 m$ & 9.64 & 1 & 3070.85 & 0.04 \\
\hline \multirow{5}{*}{ Slope } & $0.00^{\circ}-15.00^{\circ}$ & 10.71 & 2 & 311.15 & 0.67 \\
\hline & $15.01^{\circ}-30.00^{\circ}$ & 46.07 & 5 & 561.81 & 4.20 \\
\hline & $30.01^{\circ}-45.00^{\circ}$ & 24.64 & 4 & 540.01 & 2.46 \\
\hline & $45.01^{\circ}-60.00^{\circ}$ & 11.13 & 3 & 369.59 & 0.80 \\
\hline & $>60.01^{\circ}$ & 7.14 & 1 & 87.05 & 1.12 \\
\hline \multirow{5}{*}{ Aspect } & Flat areas & 0.00 & 1 & 0.00 & 0.00 \\
\hline & Southeast (SE) & 9.29 & 2 & 464.99 & 0.34 \\
\hline & Northeast (NE) & 17.14 & 3 & 434.58 & 0.79 \\
\hline & Southwest (SW) & 28.93 & 4 & 464.69 & 1.60 \\
\hline & Northwest (NW) & 44.64 & 5 & 505.27 & 2.10 \\
\hline \multirow{6}{*}{ Precipitation } & $0-1000 \mathrm{~mm}$ & 1.79 & 1 & 12.87 & 0.42 \\
\hline & $1000-1200 \mathrm{~mm}$ & 4.28 & 2 & 31.25 & 0.93 \\
\hline & $1200-1400 \mathrm{~mm}$ & 28.93 & 5 & 410.56 & 1.29 \\
\hline & $1400-1600 \mathrm{~mm}$ & 34.29 & 6 & 656.25 & 1.94 \\
\hline & $1600-1800 \mathrm{~mm}$ & 23.21 & 4 & 481.08 & 1.20 \\
\hline & $>1800 \mathrm{~mm}$ & 7.50 & 3 & 277.69 & 0.99 \\
\hline \multirow{5}{*}{ Land use } & Coniferoustrees & 6.79 & 1 & 586.61 & 0.21 \\
\hline & Deciduous trees & 10.71 & 2 & 185.83 & 1.09 \\
\hline & Wooded land & 24.64 & 3 & 964.90 & 0.65 \\
\hline & Structured land & 27.14 & 4 & 64.27 & 2.83 \\
\hline & Bare rocks & 30.72 & 5 & 68.10 & 2.90 \\
\hline
\end{tabular}

The AHP methodology consists of pairwise comparison of all possible pairs of factors and tries to synthesize the judgments to determine the weights (Saaty \& Vargas, 2001). In the specific study the relative rating for the dominance between each pair of factors was mainly guided by expert knowledge. Thus, a comparison matrix of scores was created in Table 2. Additionally, in this study, 
Table 2. Pairwise comparison matrix of scores for calculating weights.

\begin{tabular}{|c|c|c|c|c|c|c|c|c|c|}
\hline & $\begin{array}{l}\text { LITHO } \\
\text { LOGY }\end{array}$ & $\begin{array}{l}\text { PERME } \\
\text { ABILITY }\end{array}$ & ELEVATION & SLOPE & $\begin{array}{l}\text { RAIN } \\
\text { FALL }\end{array}$ & $\begin{array}{l}\text { LAND } \\
\text { USE }\end{array}$ & ASPECT & $\begin{array}{l}\text { DIST. } \\
\text { RIVER }\end{array}$ & $\begin{array}{c}\text { DIST. } \\
\text { FAULTS }\end{array}$ \\
\hline $\begin{array}{l}\text { LITHO } \\
\text { LOGY }\end{array}$ & 1.00 & 2.00 & 2.00 & 3.00 & 4.00 & 3.00 & 3.00 & 4.00 & 7.00 \\
\hline $\begin{array}{l}\text { PERME } \\
\text { ABILITY }\end{array}$ & 0.50 & 1.00 & 3.00 & 3.00 & 3.00 & 4.00 & 3.00 & 4.00 & 7.00 \\
\hline ELEVATION & 0.50 & 0.33 & 1.00 & 3.00 & 2.00 & 3.00 & 4.00 & 3.00 & 7.00 \\
\hline SLOPE & 0.33 & 0.33 & 0.33 & 1.00 & 2.00 & 2.00 & 1.00 & 2.00 & 4.00 \\
\hline $\begin{array}{l}\text { RAIN } \\
\text { FALL }\end{array}$ & 0.25 & 0.33 & 0.50 & 0.50 & 1.00 & 2.00 & 2.00 & 2.00 & 3.00 \\
\hline $\begin{array}{l}\text { LAND } \\
\text { USE }\end{array}$ & 0.33 & 0.25 & 0.33 & 0.50 & 0.50 & 1.00 & 2.00 & 100 & 4.00 \\
\hline ASPECT & 0.33 & 0.33 & 0.25 & 1.00 & 0.50 & 0.50 & 1.00 & 2.00 & 3.00 \\
\hline $\begin{array}{l}\text { DIST. } \\
\text { RIVER }\end{array}$ & 0.25 & 0.25 & 0.25 & 0.50 & 0.50 & 1.00 & 0.50 & 1.00 & 3.00 \\
\hline $\begin{array}{c}\text { DIST. } \\
\text { FAULTS }\end{array}$ & 0.14 & 0.14 & 0.17 & 0.25 & 0.33 & 0.25 & 0.33 & 0.33 & 1.00 \\
\hline WHEIGHTS & 0.243 & 0.218 & 0.167 & 0.089 & 0.080 & 0.065 & 0.063 & 0.049 & 0.023 \\
\hline
\end{tabular}

CONSISTENCY RATIO $(\mathrm{CR})=0.04$.

consistency ratio value is obtained by the ratio between the values of the consistency indexes [that is matrix's consistency index whose expression is shown in Equation (2)] and a random index, which actually is the average consistency index. It is noted that a consistency ratio with value lower than 0.1 would be acceptable, although this depends on the objective of the study (Ayalew et al., 2004).

$$
C I=\frac{\lambda_{\max }-m}{m-1}
$$

where $\lambda_{\max }$ is the maximum eigenvalue of comparison matrix and $\mathrm{m}$ is the number of the factors ( 9 in this study).

\section{Validation and Results}

After acquiring the weights of landslide parameters, they are multiplied in the map, calculated by frequency ratio and fuzzy membership. The result of them is shown subsequently in Figure 3. The output landslide susceptibility map from the fuzzy analytical hierarchy process model (FAHP), which is depicted in Figure 4, is showing that almost $35 \%$ (equals to $649 \mathrm{~km}^{2}$ ) and $10 \%$ (equals to 187 $\mathrm{km}^{2}$ ) of the study area were classified as "High" and "Very High" susceptibility zones, respectively. The same map shows also that the previous mentioned zones are located around the southern and northern part of Evritania prefecture. Fur- 
thermore, the overlay of the final landslide susceptibility map with the landslide training dataset indicated that $27 \%, 38 \%$ and $28 \%$ (total: $93 \%$ ) of landslide events fall within "Moderate", "High" \& "Very High" landslide susceptibility zones (in total $78 \%$ of the study area), respectively.
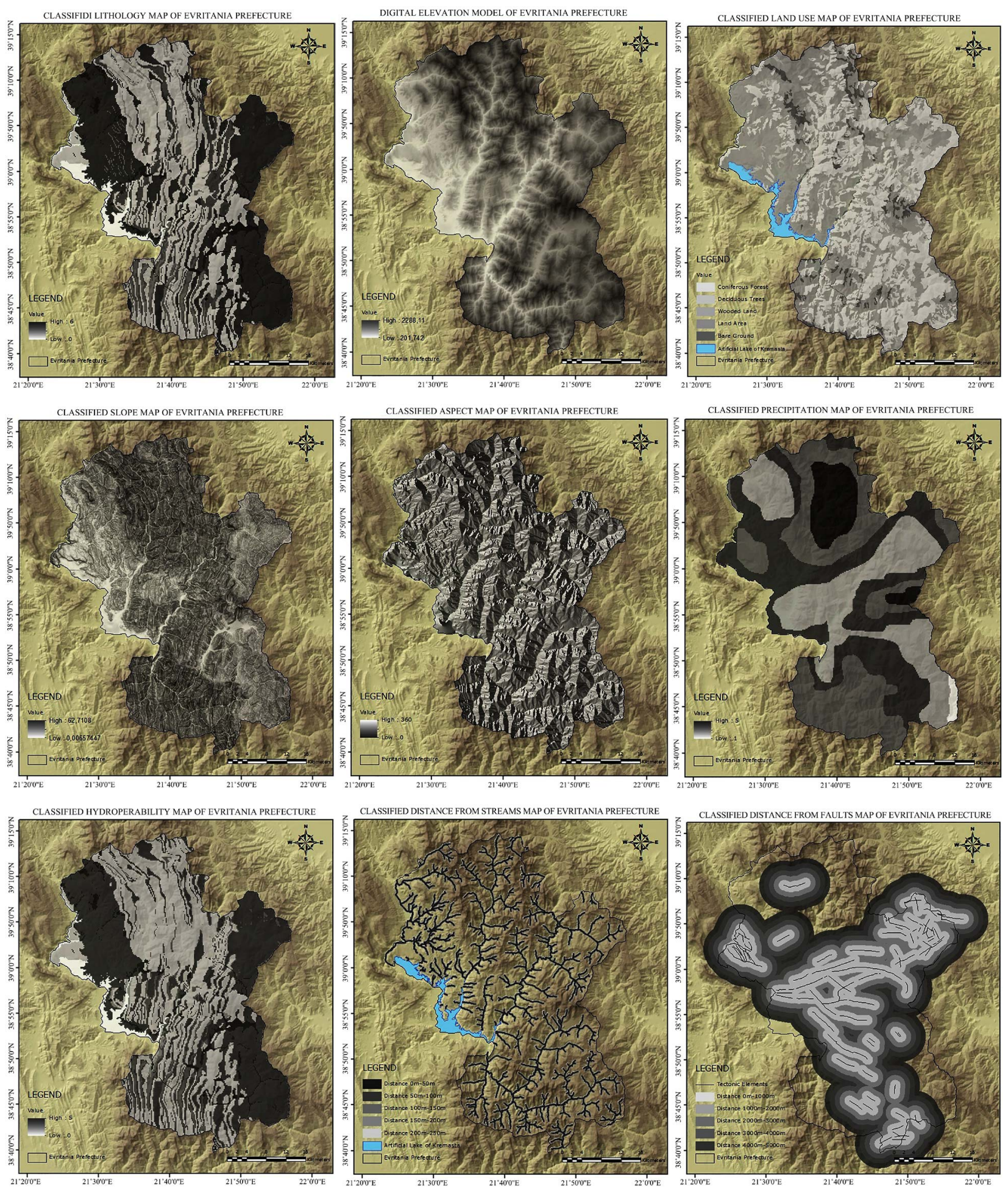

Figure 3. Weighted factors input data layers. 

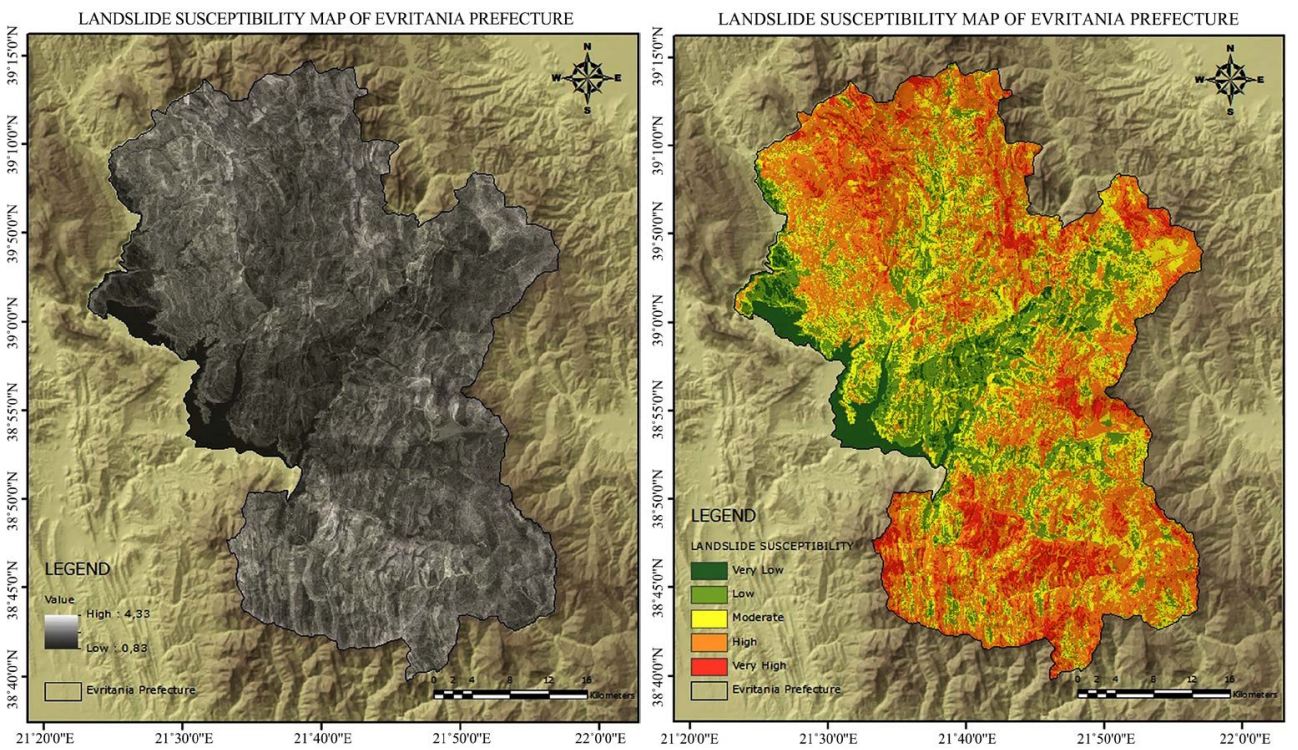

Figure 4. Landslide susceptibility maps.

It is notable that according to the used model only $6 \%$ of the landslide test set falls in "Low" susceptibility zone, with almost no landslides into the "Very Low" susceptibly zone. To conclude, the statistical numbers that arise from FAHP analysis are summarized in Table 3.

At the end, maps obtained using FAHP of each factor and incorporated so that may have the landslide hazard zonation map based on the most susceptible operator using the Equation (3) that follows (Malekian et al., 2012).

$$
\mu_{\text {combination }}=1-\prod_{i=1}^{m}\left[1-\mu_{i}(x)\right]
$$

where $\mu_{i}$ is the fuzzy membership function for its map and $i$ the number of maps that have been combined (Zimmerman, 1996). Then, the final map as it is shown below was classified into five classes based on standard deviation (see Figure 4).

In order to evaluate these classification methods, the landslide-susceptibility analysis results were verified using the existing landslide locations in the study area and "ROC" (Receiver Operating Characteristics) method. This ROC-curve is obtained by plotting all combinations of sensitivities (on the y-axis) and proportions of false negatives (on the $\mathrm{x}$-axis) that may be obtained by varying the decision threshold (Brenning, 2005). It is mentioned that the area under cover defines the quality of the probabilistic model by describing its ability to reliably predict an occurrence or non-occurrence event (Remondo et al., 2003). An ideal model presents an AUC value close to 1.0; whereas a value close to 0.5 indicates inaccuracy in the model (Fawcett, 2006). In the AUC methods, the AUC with values ranging from 0.5 to 1.0 is used to assess the accuracy of the constructed model. The AUC value of the ROC curve for this study was found to be 0.7667 as it is noted in left side of Figure 5 and on the right it is shown a landslide area from Evritania prefecture located near to city of Karpenisi.

Also, in Figure 6 are providing the results from landslide susceptibility map for each vulnerable zone separate. 
Table 3. Results using the fuzzy analytical hierarchy process model (FAHP).

\begin{tabular}{cccc}
\hline $\begin{array}{c}\text { Susceptibility } \\
\text { classes (zonation) }\end{array}$ & $\begin{array}{c}\text { Area of } \\
\text { each class (\%) }\end{array}$ & $\begin{array}{c}\text { Cell landslide } \\
\text { frequency (\%) }\end{array}$ & $\begin{array}{c}\text { Relative frequency of } \\
\text { landslides (\%) }\end{array}$ \\
\hline Very Low & 4.43 & 1.05 & 1.35 \\
Low & 17.88 & 5.75 & 6.21 \\
Moderate & 32.72 & 26.67 & 22.78 \\
High & 34.71 & 38.23 & 32.46 \\
Very High & 10.26 & 28.30 & 37.20 \\
\hline
\end{tabular}
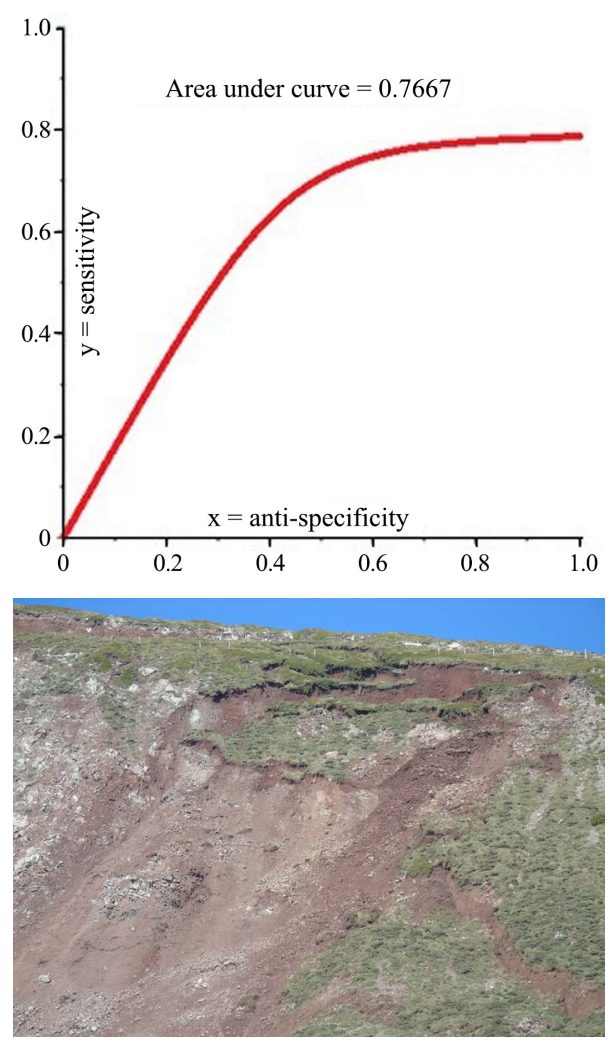

Figure 5. ROC curve LS maps produced in this study (left)-Landslide event (right).

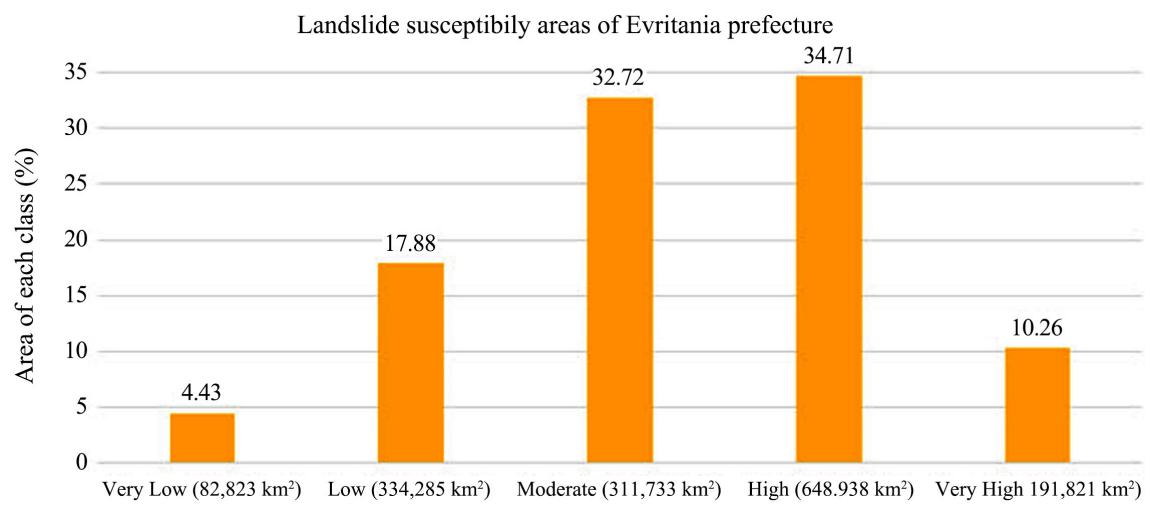

Figure 6. Histogram of LS map showing the relative areas for each susceptibility class. 


\section{Discussion and Conclusion}

This study was aimed at assessing the landslide susceptibility at a prefecture scale $(1: 50,000)$ on the central Greece. By applying a statistical analysis, implemented in a Geographic Information System environment, the relationships between landslide events and geo-environmental factors were assessed and shown on susceptibility map. Despite the helpful usage of the model, the choice of these factors plays a major role in the relative accuracy of the outcomes. Limited emphasis has been directed towards selection. The literature indicates that the most common conditioning factors are: lithological units, tectonic features, slope angle, proximity to (road or drainage) networks, land use and rainfall distribution. All of these factors are considered to be related to landslide occurrence. However, there are additional factors that may be arguably as influential. Crucial factors for landslide susceptibility in the study area are lithology, land cover, altitude, slope, aspect, hydroperability, precipitation, distance from streams and distance from tectonic elements. According to lithology, two (2) units are the most important: flysch and quaternary sediments. The most important topographic factor is slope angle, especially from $15^{\circ}$ to $30^{\circ}$. Land use has a significant impact on bare ground and in land area, while impermeable formations have the tendency to demonstrate landslide phenomenon. Landslide is one of environmental phenomena, which occur in some parts of Evritania prefecture.

Therefore, creation of one regional strategy is very necessary to reduce its damages and maintains natural and human resources. In this study, based on Fuzzy Logic, Frequency Ratio and Analytical Hierarchy Process model and nine data layers the landslide susceptibility in Evritania prefecture was assessed, then using ROC curve, these results were verified. The assessment results show that in the relatively safe areas, almost $45 \%$ of landslides are distributed in the "Very High" and "High" areas, while less than 23\% of landsides occur in the "Very Low" and "Low" areas. According to landslide susceptibility map, most agriculture areas together with the pasture fall in both very high and high susceptible zone and most of very low and low class fall into dense forest area, indicating that human activities played an important role in the landslide occurrence.

Thus, the results of such studies can be used for mitigating the hazard and is very helpful to planners and engineers for choosing suitable locations to carry out developments. To prevent the risks of landslide in the study area it is recommended to prevent degradation and change in natural vegetation. Additionally, planners and developers could potentially use this hazard map to identify roads and settlements subject to damage by future landslides, and take drastic measures for preventing the landslide events.

\section{Acknowledgements}

The authors would like to thank the mayor of Karpenisi for his support and the Institute of Geology and Mineral Exploration in Greece (IGME) for data acquisition. 


\section{Conflicts of Interest}

The authors declare no conflicts of interest regarding the publication of this paper.

\section{References}

Ayalew, L., \& Yamagishi, H. (2005). The Application of GIS-Based Logistic Regression for Landslide Susceptibility Mapping in the Kakuda-Yahiko Mountains, Central Japan. Geomorphology, 65, 15-31. https://doi.org/10.1016/j.geomorph.2004.06.010

Ayalew, L., Yamagishi, H., \& Ugawa, N. (2004). Landslide Susceptibility Mapping Using GIS Based Weighted Linear Combination, the Case in Tsugawa Area of Agano River, Niigata Prefecture, Japan. Landslides, 1, 73-81.

https://doi.org/10.1007/s10346-003-0006-9

Bonham-Carter, G. F. (1994). Geographic Information Systems for Geoscientists, Modeling with GIS (398 p). Oxford: Pergamon.

Brabb, E. E. (1984). Innovative Approaches to Landslide Hazard Mapping. Proceedings of 4th International Symposium on Landslides, 1, 307-324.

Brenning, A. (2005). Spatial Prediction Models for Landslide Hazards: Review, Comparison and Evaluation. Natural Hazards and Earth System Sciences, 5, 853-862. https://doi.org/10.5194/nhess-5-853-2005

Caniani, D., Pascale, S., Sado, F., \& Sole, A. (2008). Neural Networks and Landslide Susceptibility: A Case Study of the Urban Area of Potenza. Natural Hazards, 45, 55-72. https://doi.org/10.1007/s11069-007-9169-3

Carrara, A. (1983). A Multivariate Model for Landslide Hazard Evaluation. Journal of the International Association for Mathematical Geology, 15, 403-426. https://doi.org/10.1007/BF01031290

Champati Ray, P. K., Dimri, S., Lakhera, R. C., \& Sati, S. (2007). Fuzzy-Based Method for Landslide Hazard Assessment in Active Seismic Zone of Himalaya. Landslides, 4, 101-111. https://doi.org/10.1007/s10346-006-0068-6

Cheng, Z., \& Wang, J. (2007). Landslide Hazard Mapping Using Logistic Regression Model in Valley of Mackenzie, Canada. Natural Hazards, 42, 75-89. https://doi.org/10.1007/s11069-006-9061-6

Conforti, M., Robustelli, G., Muto, F., \& Critelli, S. (2012). Application and Validation of Bivariate GIS-Based Landslide Susceptibility Assessment for the Vitravo River Catchment (Calabria, South Italy). Natural Hazards, 61, 127-141.

https://doi.org/10.1007/s11069-011-9781-0

Creighton, R. (2006). A Report of the Irish Landslides Working Group (pp. 1-109). Geological Survey of Ireland 2006.

Crozier, M. J., \& Glade, T. (2005). Landslide Hazard and Risk: Issues, Concepts and Approach. In T. Glade, M. G. Anderson, \& M. J. Crozier, Eds., Landslide Risk Assessment (pp. 1-40). New York: John Wiley. https://doi.org/10.1002/9780470012659.ch1

Dai, F. C., Lee, C. F., Li, J., \& Xu, Z. W. (2001). Assessment of Landslide Susceptibility on the Natural Terrain of Lantau Island, Hong Kong. Environmental Geology, 40, 381-391. https://doi.org/10.1007/s002540000163

Ercanoglu, M., \& Gokceoglu, C. (2004). Use of Fuzzy Relations to Produce Landslide Susceptibility Map of a Landslide Prone Area West Black Sea Region, Turkey. Engineering Geology, 75, 229-250. https://doi.org/10.1016/j.enggeo.2004.06.001

Faraji Sabokbar, H., Shadman Roodposhti, M., \& Tazik, E. (2014). Landslide Susceptibili- 
ty Mapping Using Geographically-Weighted Principal Component Analysis. Geomorphology, 226, 15-24. https://doi.org/10.1016/j.geomorph.2014.07.026

Fawcett, T. (2006). An Introduction to ROC Analysis. Pattern Recognition Letters, 27, 861-874. https://doi.org/10.1016/j.patrec.2005.10.010

Gee, M. D. (1991). Classification of Landslide Hazard Zonation Methods and a Test of Predictive Capability. Proceeding of 6th International Symposium on Landslides, 2, 947-952.

Hatamifar, R., Mousavi, S. H., \& Alimoradi, M. (2012). Landslide Hazard Zonation Using AHP Model and GIS Technique in Khoram City. Geomorphology and Environmental Planning, 23, 43-60.

Iovine, G. (2008). Mud-Flow and Lava-Flow Susceptibility and Hazard Mapping through Numerical Modelling, GIS Techniques, Historical and Geo-Environmental Analyses. Proceedings of the iEMSs 4th Biennial Meeting, International Congress on Environmental Modelling ANS Software: Integrating Sciences and Information Technology for Environmental Assessment and Decision Making (iEMSs2008), 3, 1447-1460.

Jordan, C., O'Connor, E., Marchant, A., Northmore, A., Greenbaum, D., McDonald, A., Kovacik, M., \& Ahmed, R. (2000). Rapid Landslide Susceptibility Mapping Using RS and GIS Modelling. In Proceedings of 14th International Conference on Applied Geologic Remote Sensing (pp. 113-120). Las Vegas, NV.

Kayastha, P., Dhital, M. R., \& Smedt, F. D. (2013). Application of the Analytical Hierarchy Process (AHP) for Landslide Susceptibility Mapping: A Case Study from the Tinau Watershed, West Nepal. Computers \& Geosciences, 52, 398-408.

https://doi.org/10.1016/j.cageo.2012.11.003

Khezri, S. (2010). Landslide Susceptibility in the Zab Basin, Northwest of Iran. Procedia-Social and Behavioral Sciences, 19, 726-731. https://doi.org/10.1016/j.sbspro.2011.05.191

Liu et al., (2007). Using Fuzzy Analytical Hierarchy Process (AHP) to Evaluate Web Development Platform. Management Science Letters, 2, 253-262. https://doi.org/10.5267/j.msl.2011.08.015

Malekian, A., Oftadegan Khuzani, A., \& Ashurnejad, G. (2012). Flood Hazard Zoning in Watershed Scale Using Fuzzy Logic (Case Study: Akhtar Abad Watershed). Physical

Perriello Zampelli, S., Bellucci Sessa, E., \& Cavallaro, M. (2012). Application of a GIS-Aided Method for the Assessment of Volcaniclastic Soil Sliding Susceptibility to Sample Areas of Campania (Southern Italy). Natural Hazards, 61, 155-168. https://doi.org/10.1007/s11069-011-9807-7

Pourghasemi, M., Hamid, R., Fatemi, A., Said, M., Mahdavifar, M. R., \& Mohammdi, M. (2009). Landslide Hazard Assessment Using Fuzzy Multi Criteria Decision-Making Method. Iranian Journal of Watershed Management Science \& Engineering, 3, 51-62.

Remondo, J., Gonzàlez-Diez, A., Dìaz de Teràn, J. R., \& Cendrero, A. (2003). Landslides Susceptibility Models Utilising Spatial Data Analysis Techniques. A Case Study from the Lower Deba Valley, Guipùzcoa (Spain). Natural Hazards, 30, 267-279. https://doi.org/10.1023/B:NHAZ.0000007202.12543.3a

Saaty, L. T., \& Vargas, L. G. (2001). Models, Methods, Concepts, and Applications of the Analytic Hierarchy Process (p. 333). Boston, MA: Kluwer Academic. https://doi.org/10.1007/978-1-4615-1665-1

Zimmerman, H. J. (1996). Fuzzy Set Theory and Its Applications (435 p). Boston, MA: Kluwer. https://doi.org/10.1007/978-94-015-8702-0 